\title{
NUMERICAL AND EXPERIMENTAL STUDIES ON ALUMINUM SANDWICH PLATES OF VARIABLE THICKNESS
}

\author{
Jeng-Shian Chang*, Hong-Chung Chen, and Han-Ting Lin
}

\begin{abstract}
The elastic flexural behavior of static deformation and free vibration of sandwich plates of variable thickness is investigated numerically and experimentally. In the analysis, the face plates are treated as Marguerre shells, and the core is assumed to be an antiplane core and to provide resistance to transverse shear and normal stresses only. Displacement continuity conditions are used at the interfaces between face plates and the core to derive the displacement field. Energy formulations are obtained and solved by the isoparametric finite element method. The numerical results are obtained to compare with the results in the existing literature and to show the effects of taper constant and face plate thickness on deflections and natural frequencies. Finally, experimental works based on the method of holographic interferometry are conducted to confirm the theoretical findings. Experimental and numerical data agree quite well in this work.
\end{abstract}

Key Words: sandwich plate, variable thickness, finite element method, holographic interferometry.

\section{INTRODUCTION}

Sandwich plates have been adopted in the structures of aircrafts, ships and architecture because of high specific bending stiffness ratio, damping character, nice fatigue property and variety of design. It is necessary to develop an analytic theory for sandwich plates of variable thickness for the streamlined requirement of airfoils, empennages, propellers, etc. Most studies on sandwich construction followed elastic plate and shell theories. In the analysis of uniform sandwich plate with isotropic or orthotropic characters, Plantema (1969) and Allen (1969) provided general discussion on bending and stability of sandwich plate. In addition, transverse shear deformation should be considered. Reissner (1947; 1948) showed that the formula for sandwich plate was the same in form as the uniform plate formula, in which shear strain was considered, assuming membrane-plate bending stiffness was neglected and the antiplane core with stress parallel to plate was neglected. In vibration analysis, Yu (1960a; 1960b) found that transverse

*Corresponding author. (Tel: 886-2-33665678; Email jschang@gauss.iam.ntu.edu.tw)

J. S. Chang and H. T. Lin are with the Institute of Applied Mechanics, National Taiwan University, Taipei 106, Taiwan.

H. C. Chen is with the Department of Naval Architecture, National Kaohsiung Marine University, Kaohsiung 811, Taiwan. shear deformation, moving inertia of face plate and core-plate and rotation inertia of the middle face of the sandwich plate all should be taken into consideration.

Furthermore, Huang and Alspaugh (1974) and Lee and Yu (1985) adopted the theory of uniform thickness plates and local stiffness varies with position of plate to study sandwich plates of variable thickness. Paydar and Libove $(1986 ; 1988)$ and Paydar (1988) considered static behavior of variablethickness sandwich plates, assuming the faces to behave as membranes, and showed that significant errors could arise when neglecting the contribution of the face plate membrane forces to the transverse shear in weak core cases. In addition, in their experimental work, Libove and Lu $(1989 ; 1991)$ confirmed the slope effect of sandwich plates of variable thickness. However, their work could not be expanded for general cases.

Following the above, Chang and Chen (1992) considered the face plates of sandwich plates of variable thickness as constant thicknesses and assumed them to act as Marguerre shallow shells to take into account both membrane forces and bending moments, but with the non-linear terms neglected owing to the small amplitude of vibration assumed. In addition, the core was assumed to be an antiplane core which bears transverse normal and shear stresses only. 
In this paper, a similar model has been adopted. Also, two relatively simplified models are proposed for efficiency in computation. The deflection and vibration of aluminum sandwich plates of variable thickness are studied numerically and experimentally based on holographic interferometry. The numerical results have been compared with the analytic solutions in the existing literature to show the correctness and limitations of the three proposed models. Finally, the holographic experimental data agree rather well with the numerical predictions, which confirm the proposed theoretical models in this work.

\section{GENERAL FORMULATIONS}

\section{Displacement, Strain, Stress and Energy Equa- tions}

The core of a sandwich plate is allowed to be variable in thickness in both in-plane directions and is made of low density material, thicker than face plate. Blankets of core are the upper and lower stiffer aluminum face plates. The notations for the displacements and the geometric relations of the sandwich plates are shown in Fig. 1. The subscripts $f=1,2$ are used to denote quantities associated with the upper and lower face plates, while the subscript $c$ refers to quantities associated with the core. Let $z=z_{f}(x, y)$ denote the thickness direction of global coordinates of the undeformed middle surface of the plate. The local coordinates of the face plate, referred to its own mid-plane, are represented by $\left(x, y, z_{l f}\right)$. In Marguerre shallow shell theory (Marguerre, 1938), with a Mindlin formulation (Pica and Wood, 1980), the gross displacements $\boldsymbol{u}_{f}=\left[u_{f}, v_{f}, w_{f}\right]^{T}$ at $\left(x, y, z_{l f}\right)$ are expressed as functions of the mid-plane translations of the face plates $\bar{u}_{f}, \bar{v}_{f}$ and $\bar{w}_{f}$ and the rotations $\theta_{f x}$ and $\theta_{f y}$ as

$$
\boldsymbol{u}_{f}=\left\{\begin{array}{c}
u_{f} \\
v_{f} \\
w_{f}
\end{array}\right\}=\left\{\begin{array}{c}
\bar{u}_{f}+z_{l f} \boldsymbol{\theta}_{f x} \\
\bar{v}_{f}+z_{l f} \boldsymbol{\theta}_{f y} \\
\bar{w}_{f}
\end{array}\right\} .
$$

The position vectors of an arbitrary point of the face plate, before and after deformation, are given by $\boldsymbol{r}_{f}^{(i)}$ and $\boldsymbol{r}_{f}^{(f)}$, respectively:

$$
\boldsymbol{r}_{f}^{(i)}=\left\{\begin{array}{c}
x-z_{l f} \frac{\partial z_{f}}{\partial x} \\
y-z_{l f} \frac{\partial z_{f}}{\partial y} \\
z_{f}+z_{l f}
\end{array}\right\}, \boldsymbol{r}_{f}^{(f)}=\left\{\begin{array}{c}
x+\bar{u}_{f}+z_{l f}\left(\boldsymbol{\theta}_{f x}-\frac{\partial z_{f}}{\partial x}\right) \\
y+\bar{v}_{f}+z_{l f}\left(\boldsymbol{\theta}_{f y}-\frac{\partial z_{f}}{\partial y}\right) \\
z_{f}+\bar{w}_{f}+z_{l f}
\end{array}\right\} .
$$

Neglecting thickness of adhesive film and assuming first order deformation, the displacement of the core $\boldsymbol{u}_{c}$, can be written as

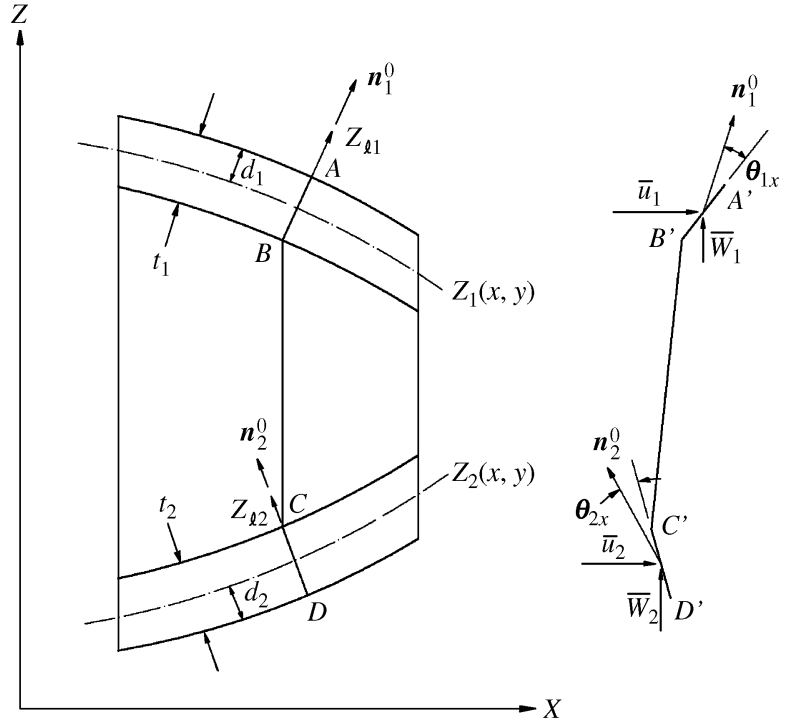

Fig. 1 Displacements and geometry of a variable thickness sandwich plate

$$
\begin{aligned}
& \boldsymbol{u}_{c}= \frac{1}{2}\left(\boldsymbol{u}_{1 a}+\boldsymbol{u}_{2 a}\right)+\frac{z_{c}}{t_{c}}\left(\boldsymbol{u}_{1 a}-\boldsymbol{u}_{2 a}\right) \\
&=\left\{\begin{array}{c}
u_{c} \\
v_{c} \\
w_{c}
\end{array}\right\}=\left\{\begin{array}{c}
\frac{1}{2}\left(\bar{u}_{1}+\bar{u}_{2}-d_{1} \theta_{1 x}+d_{2} \theta_{2 x}\right) \\
+\frac{z_{c}}{t_{c}}\left(\bar{u}_{1}-\bar{u}_{2}-d_{1} \theta_{1 x}-d_{2} \theta_{2 x}\right) \\
\frac{1}{2}\left(\bar{v}_{1}+\bar{v}_{2}-d_{1} \theta_{1 y}+d_{2} \theta_{2 y}\right) \\
+\frac{z_{c}}{t_{c}}\left(\bar{v}_{1}-\bar{v}_{2}-d_{1} \theta_{1 y}-d_{2} \theta_{2 y}\right) \\
\frac{1}{2}\left(\bar{w}_{1}+\bar{w}_{2}\right)+\frac{z_{c}}{t_{c}}\left(\bar{w}_{1}-\bar{w}_{2}\right)
\end{array}\right\},
\end{aligned}
$$

where $\boldsymbol{u}_{1 a}$ and $\boldsymbol{u}_{2 a}$ are displacements at the interfaces between the core and two face plates 1, 2 respectively, $t_{c}$ is the thickness of the core and may be different from point to point, and $z_{c}$ is the local co-ordinate in the thickness direction of the core.

From Green's strain tensor definition (Washizu, 1975), the strains of the face plate, before and after deformation, are given by $e_{f i j}^{(i)}$ and $e_{f i j}^{(f)}$ respectively:

$$
\begin{aligned}
& e_{f i j}^{(i)}=\frac{1}{2}\left[\frac{\partial \boldsymbol{r}_{f}^{(i)}}{\partial x_{i}} \cdot \frac{\partial \boldsymbol{r}_{f}^{(i)}}{\partial x_{j}}-\frac{\partial \boldsymbol{r}_{f}^{(0)}}{\partial x_{i}} \cdot \frac{\partial \boldsymbol{r}_{f}^{(0)}}{\partial x_{j}}\right] \\
& e_{f i j}^{(f)}=\frac{1}{2}\left[\frac{\partial \boldsymbol{r}_{f}^{(f)}}{\partial x_{i}} \cdot \frac{\partial \boldsymbol{r}_{f}^{(f)}}{\partial x_{j}}-\frac{\partial \boldsymbol{r}_{f}^{(0)}}{\partial x_{i}} \cdot \frac{\partial \boldsymbol{r}_{f}^{(0)}}{\partial x_{j}}\right] .
\end{aligned}
$$

Substituting Eq. (2) into (4) and (5), and neglecting the non-linear terms of small displacements $\bar{u}_{f}, \bar{v}_{f}$ and $\bar{w}_{f}$, gives the linearized Green's strains of the plates, namely, the in-plane strain $\left\{e_{f}\right\}$ and the out-of -plane strain $\left\{\gamma_{f}\right\}$, as 


$$
\begin{aligned}
\left\{e_{f}\right\}=\left\{\begin{array}{c}
e_{f x} \\
e_{f y} \\
\gamma_{f x y}
\end{array}\right\}=\left\{\begin{array}{c}
\frac{\partial \bar{u}_{f}}{\partial x} \\
\frac{\partial \bar{v}_{f}}{\partial y} \\
\partial \bar{u}_{f} \\
\frac{\partial y}{\partial y}+\frac{\partial \bar{v}_{f}}{\partial x}
\end{array}\right\} \\
+\left\{\begin{array}{c}
\frac{\partial z_{f}}{\partial x} \frac{\partial \bar{w}_{f}}{\partial x} \\
\frac{\partial z_{f}}{\partial y} \frac{\partial \bar{w}_{f}}{\partial y} \\
\frac{\partial z_{f}}{\partial x} \frac{\partial \bar{w}_{f}}{\partial y}+\frac{\partial z_{f}}{\partial y} \frac{\partial \bar{w}_{f}}{\partial x}
\end{array}\right\}+z_{l f}\left\{\begin{array}{c}
\frac{\partial \theta_{f x}}{\partial x} \\
\frac{\partial \theta_{f y}}{\partial y} \\
\frac{\partial \theta_{f x}}{\partial y}+\frac{\partial \theta_{f y}}{\partial x}
\end{array}\right\} \\
=\left\{e_{f 01}\right\}+\left\{e_{f 02}\right\}+z_{l f}\left\{k_{f 0}\right\}=\left\{e_{f 0}\right\}+z_{l f}\left\{k_{f 0}\right\}
\end{aligned}
$$

$$
\left\{\gamma_{f}\right\}=\left\{\begin{array}{l}
\gamma_{f y z} \\
\gamma_{f z x}
\end{array}\right\}+\left\{\begin{array}{c}
\theta_{f y}+\frac{\partial \bar{w}_{f}}{\partial y} \\
\theta_{f x}+\frac{\partial \bar{w}_{f}}{\partial z}
\end{array}\right\},
$$

where $\left\{e_{f 0}\right\}$ are the total strains at the face plate of mid-plan, which include $\left\{e_{f 01}\right\}$, the general membrane strains, and $\left\{e_{f 02}\right\}$, the additional linear membrane strains due to the undeformed shape of the face plate; $\left\{k_{f 0}\right\}$ and $\left\{\gamma_{f}\right\}$ are the bending strains and transverse shear strains. Note that the term $\left\{e_{f 02}\right\}$ takes into account the effect of variable thickness of core or non-flatness of the face plates of shallow shell type sandwich plates; in the case of uniform thickness sandwich plates, $z_{f}$ is constant and $\left\{e_{f 02}\right\}$ vanishes. Due to the assumption of antiplane core, only the normal strain $e_{c z}$ on the $z$ plane and transverse shear strain $\left\{\gamma_{c}\right\}$ of the core should be considered and may be written as

$$
\begin{aligned}
& e_{c z}= \frac{\partial w_{c}}{\partial z}=\frac{1}{t_{c}}\left(\bar{w}_{1}-\bar{w}_{2}\right) \\
&\left\{\gamma_{c}\right\}=\left\{\begin{array}{l}
\gamma_{c y z} \\
\gamma_{c z x}
\end{array}\right\}=\left\{\begin{array}{l}
\frac{\partial v_{c}}{\partial z}+\frac{\partial w_{c}}{\partial y} \\
\frac{\partial u_{c}}{\partial z}+\frac{\partial w_{c}}{\partial x}
\end{array}\right\} \\
&=\left\{\begin{array}{c}
\frac{1}{t_{c}}\left(\bar{v}_{1}-\bar{v}_{2}-d_{1} \theta_{1 y}-d_{2} \theta_{2 y}\right) \\
+\frac{1}{2}\left(\frac{\partial \bar{w}_{1}}{\partial y}+\frac{\partial \bar{w}_{2}}{\partial y}\right) \\
\frac{1}{t_{c}}\left(\bar{u}_{1}-\bar{u}_{2}-d_{1} \theta_{1 x}-d_{2} \theta_{2 x}\right) \\
+\frac{1}{2}\left(\frac{\partial \bar{w}_{1}}{\partial x}+\frac{\partial \bar{w}_{2}}{\partial x}\right)
\end{array}\right\} \\
&+z_{c}\left\{\begin{array}{l}
\frac{1}{t_{c}}\left(\frac{\partial \bar{w}_{1}}{\partial y}-\frac{\partial \bar{w}_{2}}{\partial y}\right) \\
\frac{1}{t_{c}}\left(\frac{\partial \bar{w}_{1}}{\partial x}-\frac{\partial \bar{w}_{2}}{\partial x}\right)
\end{array}\right\} \\
&=\left\{\gamma_{c c}\right\}+z_{c}\left\{\gamma_{c l}\right\},
\end{aligned}
$$

where $\left\{\gamma_{c c}\right\}$ and $\left\{\gamma_{c l}\right\}$ represent the constant and linear terms of transverse shear deformation of the core, respectively, and are independent of $z_{c}$.

For a linear elastic orthotropic material, the constitutive law can be written as (Jones, 1975)

$$
\left\{\begin{array}{l}
\sigma_{x} \\
\sigma_{y} \\
\tau_{x y} \\
\tau_{y z} \\
\tau_{z x}
\end{array}\right\}=\left[\begin{array}{ccccc}
\bar{Q}_{11} & \bar{Q}_{12} & \bar{Q}_{16} & 0 & 0 \\
\bar{Q}_{12} & \bar{Q}_{22} & \bar{Q}_{26} & 0 & 0 \\
\bar{Q}_{16} & \bar{Q}_{26} & \bar{Q}_{66} & 0 & 0 \\
0 & 0 & 0 & \bar{Q}_{44} & \bar{Q}_{45} \\
0 & 0 & 0 & \bar{Q}_{45} & \bar{Q}_{55}
\end{array}\right]_{f}\left\{\begin{array}{l}
e_{f x} \\
e_{f y} \\
\gamma_{f x y} \\
\gamma_{f y z} \\
\gamma_{f z x}
\end{array}\right\},
$$

where $\bar{Q}_{i j}$ is the transformed reduced stiffness.

On the face plates, the second kind of piola kirchhoff stresses $\left\{\sigma_{f}\right\}$ and $\left\{\tau_{f}\right\}$ can be related to the Green's strains $\left\{e_{f}\right\}$ and $\left\{\gamma_{f}\right\}$ as

$$
\begin{aligned}
\left\{\sigma_{f}\right\} & =\left\{\begin{array}{c}
\sigma_{f x} \\
\sigma_{f y} \\
\sigma_{f x y}
\end{array}\right\}=\left[\begin{array}{lll}
\bar{Q}_{11} & \bar{Q}_{12} & \bar{Q}_{16} \\
\bar{Q}_{12} & \bar{Q}_{22} & \bar{Q}_{26} \\
\bar{Q}_{16} & \bar{Q}_{26} & \bar{Q}_{66}
\end{array}\right]_{f}\left\{\begin{array}{c}
e_{f x} \\
e_{f y} \\
\gamma_{f x y}
\end{array}\right\} \\
& =[\bar{Q}]_{f}\left(\left\{e_{f 0}\right\}+z_{l f}\left\{k_{f 0}\right\}\right) \\
\left\{\tau_{f}\right\} & =\left\{\begin{array}{l}
\tau_{f y z} \\
\tau_{f z x}
\end{array}\right\}=\left[\begin{array}{ll}
\bar{Q}_{44} & \bar{Q}_{45} \\
\bar{Q}_{45} & \bar{Q}_{55}
\end{array}\right]_{f}\left\{\begin{array}{l}
\gamma_{f y z} \\
\gamma_{f z x}
\end{array}\right\}=[\bar{G}]_{f}\left\{\gamma_{f}\right\} .
\end{aligned}
$$

The stress-strain relationships of the core can be written as

$$
\begin{aligned}
& \sigma_{c z}=E_{c} e_{c z} \\
& \left\{\tau_{c}\right\}=\left\{\begin{array}{l}
\tau_{c y z} \\
\tau_{c z x}
\end{array}\right\}=[G]_{c}\left\{\begin{array}{l}
\gamma_{c y z} \\
\gamma_{c z x}
\end{array}\right\}=\left[\begin{array}{ll}
G_{c 11} & G_{c 12} \\
G_{c 21} & G_{c 22}
\end{array}\right]\left\{\begin{array}{l}
\gamma_{c y z} \\
\gamma_{c z x}
\end{array}\right\},
\end{aligned}
$$

where

$$
\begin{aligned}
& G_{c 11}=G_{c y^{\prime} z} \cos ^{2} \theta_{c}+G_{c x^{\prime} z} \sin ^{2} \theta_{c} \\
& G_{c 22}=G_{c y^{\prime} z} \sin ^{2} \theta_{c}+G_{c x^{\prime} z} \cos ^{2} \theta_{c} \\
& G_{c 12}=G_{c 21}=\left(G_{c y^{\prime} z}-G_{c x^{\prime} z}\right) \sin \theta_{c} \cos \theta_{c}
\end{aligned}
$$

in which, $G_{c y^{\prime} z}$ and $G_{c x^{\prime} z}$ are the transverse shear moduli of the core principal axes $x^{\prime} y^{\prime} z$, and $\theta_{c}$ is the angle between the principal axes $x^{\prime} y^{\prime}$ of the core and global axes $x y$.

The strain energy $U_{f}$ and kinetic energy $T_{f}$ of the face plate can be expressed as 


$$
\begin{aligned}
& U_{f}=\frac{1}{2} \int_{V_{f}}\left\{\sigma_{f}\right\}^{t}\left\{e_{f}\right\} d V+\frac{1}{2} \int_{V_{f}}\left\{\tau_{f}\right\}^{t}\left\{\gamma_{f}\right\} d V \\
& T_{f}=\frac{1}{2} \int_{V_{f}} \rho_{f}\left(\dot{u}_{f}^{2}+\dot{v}_{f}^{2}+\dot{w}_{f}^{2}\right) d V,
\end{aligned}
$$

where $V_{f}$ and $\rho_{f}$ are the volume and density of the face plate.

Under the assumption of antiplane, the core is unable to bear either the in-plane energy or the bending energy. So the strain energy of the core is considered to consist only of the transverse shear strain energy and normal strain energy in the thick direction only. Thus, the strain energy $U_{c}$ and kinetic energy $T_{c}$ of the core can be expressed as

$$
\begin{aligned}
& U_{c}=\frac{1}{2} \int_{V_{c}}\left\{\tau_{c}\right\}^{t}\left\{\gamma_{f}\right\} d V+\frac{1}{2} \int_{V_{c}} \sigma_{c z} e_{c z} d V \\
& T_{c}=\frac{1}{2} \int_{V_{c}} \rho_{c}\left(\dot{u}_{c}^{2}+\dot{v}_{c}^{2}+\dot{w}_{c}^{2}\right) d V,
\end{aligned}
$$

where $V_{c}$ and $\rho_{c}$ are the volume and density of the core.

\section{Finite Element Discretization and the Three Nu- merical Models}

The displacement field $\{\delta\}$ within an element is given as a function of nine discrete nodal displacements, namely,

$$
\{\delta\}=\sum_{i=1}^{9} N_{i}\left\{\delta_{i}\right\}
$$

in which $N_{i}$ are shape functions and the nodal displacements $\left\{\delta_{i}\right\}$ are

$$
\left\{\delta_{i}\right\}=\left[\bar{u}_{1 i}, \bar{v}_{1 i}, \bar{w}_{1 i}, \theta_{1 x i}, \theta_{1 y i}, \bar{u}_{2 i}, \bar{v}_{2 i}, \bar{w}_{2 i}, \theta_{2 x i}, \theta_{2 y i}\right]^{t} .
$$

The standard isoparametric finite element discretization process has been employed for the energy equations (Zienkiewicz, 1971; Bathe, 1982). Numerical loading has been accomplished according to the obtained FEM formulation.

To simplify and accelerate the calculation, the above model can be further simplified according to the material properties, geometric characteristics and accuracy requirements. There are, totally, three numerical models proposed in this work, namely, MODELS I, II and III. MODEL I is the most complete model which is capable of describing the responses of varying loadings on sandwich plates of variable thickness. In this model, there are 10 degrees of freedom in every node of elements, as described in Eq. (21). For MODEL II, the assumptions of MODEL I

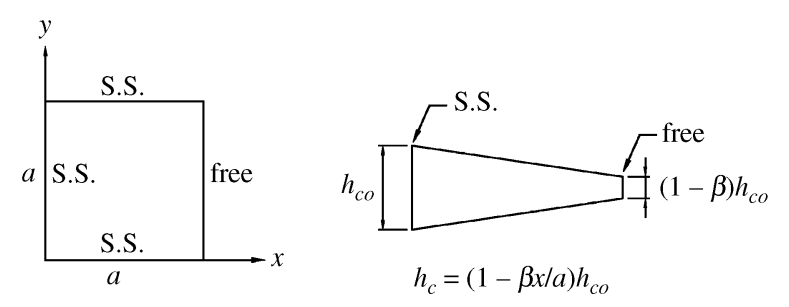

S. S.: Simple Support

Fig.2 The square plate with three edges simple supported and one edge free

are all kept except that an incompressible core in thickness direction is considered. Thus the deflections $\bar{w}_{1}$ and $\bar{w}_{2}$ of the upper and lower face plate, the rotation angles $\theta_{1 y}, \theta_{2 y}, \theta_{1 x}$ and $\theta_{2 x}$ are all considered the same. Thus, there are only 7 degrees of freedom left in every node of elements for this model, namely, $\bar{u}_{1}, \bar{v}_{1}, \bar{u}_{2}, \bar{v}_{2}, w, \theta_{x}$ and $\theta_{y}$. Finally, adding the assumption of considering the face plates as membranes, which can bear only in-plane stresses, one obtains MODEL III from MODEL II. The two degrees of freedom $\theta_{x}$ and $\theta_{y}$ are deleted based on this membrane assumption, which leaves only 5 degrees of freedom in every node of elements of MODEL III, namely, $\bar{u}_{1}$, $\bar{v}_{1}, \bar{u}_{2}, \bar{v}_{2}$, and $w$.

\section{NUMERICAL EXAMPLES AND DISCUSSION}

Two numerical examples are presented here to compare with existing analytic solutions and ensure the suitability of the proposed models in this work. The first example adopted is that given by Paydar (1985). Consider a sandwich square plate with length $a=0.508 \mathrm{~m}$ (20 inch) and with three edges simply supported and one edge free. The thickness $t_{f}$ and material property of face plates are $2.54 \times 10^{-3} \mathrm{~m}$ $\left(0.1\right.$ inch) and isotropic. The thickness $h_{c 0}$ of the core is $50.8 \times 10^{-3} \mathrm{~m}$ (2 inch) at simple supported edges and varies unidirectionally from the simply supported edge to free edge in a linear fashsion as shown in Fig. 2. A compressive loading of sine function is applied on the upper surface of the plate. The material properties, thickness of core and loading function are shown as follows,

1. face plates

$$
E_{f}=206.85 \times 10^{9} \mathrm{~Pa}\left(30 \times 10^{6} \mathrm{psi}\right) ; v_{f}=0.3
$$

2. core

$$
\begin{aligned}
& G_{c x^{\prime} z}=G_{c y^{\prime} z}=227.54 \times 10^{6} \mathrm{~Pa}(33000 \mathrm{psi}) \\
& h_{c}=h_{c o}(1-\beta \xi) ; \xi=x / a
\end{aligned}
$$




$$
q=q_{0} \sin \pi \xi \sin \pi \eta ; \eta=y / a,
$$

where $\beta$ is the taper constant of the sandwich plate. Therefore $\beta=0$ represents a plate of constant thickness; and $\beta \rightarrow 1$, a plate that tapers to a point at $x=a$.

The transverse compressive stiffness of the core here is taken as infinity to compute the deflection, which is compared with the series solution by Paydar (1985). Since the transverse compressive deformation and stiffness were not considered in Paydar's paper, only the comparable MODELS II and III are adopted in our calculation. To distinguish the slope effect and the local bending effect of the face plates, and the terms $\left\{e_{f 02}\right\}$ and $\left\{\kappa_{f 0}\right\}$ in Eq. (6), respectively, four kinds of results, SB, SM, FB and FM, are given. $\mathrm{S}, \mathrm{B}, \mathrm{M}$ and $\mathrm{F}$ are abbreviations for slope, bending, membrane and flat faces. So, for SB, both effects are taken into account; SM takes into the slope effect terms $\left\{e_{f 02}\right\}$ but without $\left\{\kappa_{f 0}\right\}$, which is the same as for membrane faces; FB keeps $\left\{\kappa_{f 0}\right\}$ but without $\left\{e_{f 02}\right\}$; FM does not take these two terms into account. The numerical results are shown in Fig. 3. The SM case in this figure agrees completely with the series solutions of Paydar (1985), and presents a little deviation from the most accurate $\mathrm{SB}$ curve as $\beta$ increases. The figure also indicates that neglecting the slope effect (FB \& FM curves) could produce large errors.

The second example considered is that given by Libove (1984), in which the beam-like vibration of sandwich plate of variable thickness was investigated. Consider a cantilever sandwich plate of variable thickness with length $a$. The thickness of core varies linearly from $h_{c 0}$ at the clamped edge to some finite thickness at the free edge end. The face plates are isotropic materials. Thickness $t_{f}$ and Young's modulus $E_{f}$ of face plates and shear modulus $G_{c}$ retain the correlation,

$$
R=\frac{E_{f} t_{f} h_{0}}{\left(2 a^{2} G_{c}\right)}=0.5
$$

Neglecting the mass of the core, a dimensionless parameter $\lambda$ can be written as,

$$
\lambda=\frac{\omega}{\omega_{r}} ; \omega_{r}=\sqrt{\frac{E_{f} t_{f} h_{0}^{2}}{2 \mu_{r} a^{4}}},
$$

where $\omega$ is natural frequency and $\mu_{r}$ is the density of sandwich plate per unit area. Pick $a=0.508 \mathrm{~m}$ (20 inch) and $h_{c 0}=50.8 \times 10^{-3} \mathrm{~m}(2$ inch). Mesh sandwich plate by $4 \times 1$ element, and constrain the boundary conditions to only vertical deflection and longitudinal deformation. The Poisson's ratio $v$ was set to zero to simulate a sandwich beam. In addition to the solution of membrane face plates of MODEL

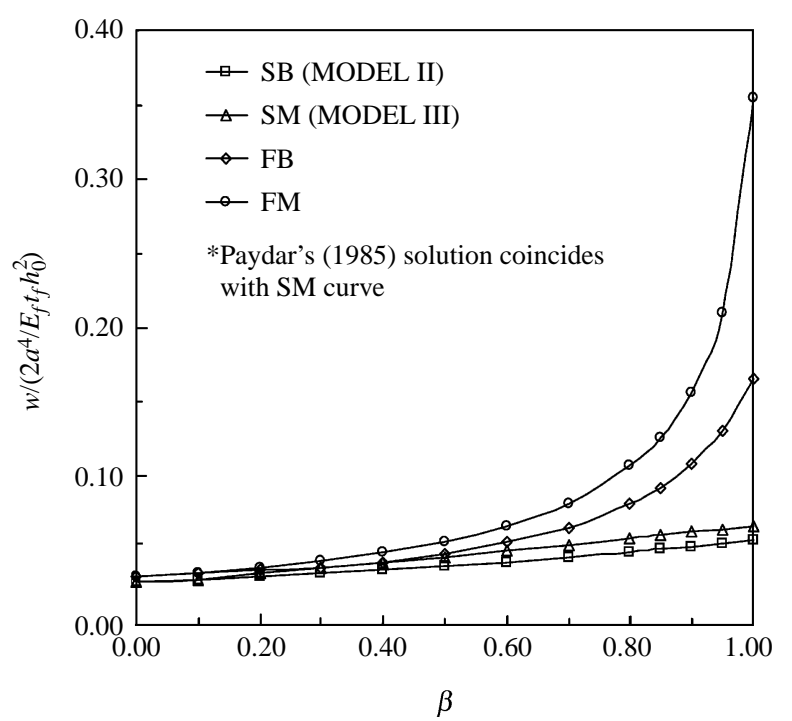

Fig.3 The relationship between taper constant $\beta$ and dimensionless deflection at middle point of free edge of square sandwich plate of variable thickness

III, solutions based on MODEL II with $t_{f}=2.54 \times$ $10^{-3} \mathrm{~m}, 2.54 \times 10^{-4} \mathrm{~m}, 2.54 \times 10^{-5} \mathrm{~m}(0.1$ inch, 0.01 inch, 0.001 inch) respectively, are also given. The numerical solutions are compared with the series solutions by Libove (1984) as shown in Table 1. Three conclusions can be obtained from Table 1. First, the correctness of our FEM codes are verified by the agreement of MODEL III with Libove's solution. Second, the bending stiffness of the face plates can be neglected when the thickness of face plate is thin. Third, the dimensionless natural frequency $\lambda$ increases as the taper constant $\beta$ gets large and the order of vibration mode increases when the thickness of the face plate grows.

\section{EXPERIMENTS AND COMPARISONS WITH NUMERICAL PREDICTIONS}

A series of holographic interferometry experiments on sandwich plates have been done to verify the correctness of the proposed numerical models. A series of square sandwich cantilever plates of variable thickness are used in the experiments as shown in Fig. 4. The core is made of hard PU foam with thickness $15 \mathrm{~mm}$ at the clamped edge varying from it to the free edge linearly, unidirectionally. The change rate of thickness can be divided into four cases, $\beta=$ $0,0.3,0.5$ and 0.9 in which $\beta=0$ represents no taper. The face plate is an aluminum square plate of 200 $\mathrm{mm} \times 200 \mathrm{~mm}, 1.61 \mathrm{~mm}$ in thickness. The clamped part is an extended part of the sandwich plate with a $200 \mathrm{~mm} \times 50 \mathrm{~mm} \times 15 \mathrm{~mm}$ iron core included. The laser path is arranged as in Fig. 5 according to the holographic interferometry of standard off-axis type. 
Table 1 Comparisons of dimensionless natural frequency $\lambda$ of cantilever sandwich plate of variable thickness

\begin{tabular}{|c|c|c|c|c|c|}
\hline \multirow{2}{*}{ Modal } & \multirow{2}{*}{\multicolumn{2}{|c|}{ Method }} & 0 & 0.5 & 0.9 \\
\hline & & & $\lambda$ & $\lambda$ & $\lambda$ \\
\hline \multirow[b]{3}{*}{1} & \multicolumn{2}{|l|}{ Libove (1984) } & 1.893 & 2.032 & 2.156 \\
\hline & \multicolumn{2}{|l|}{ MODEL III } & 1.892 & 2.032 & 2.158 \\
\hline & MODEL II & $\begin{aligned} t_{f} & =2.54 \times 10^{-5} \mathrm{~m} \\
t_{f} & =2.54 \times 10^{-4} \mathrm{~m} \\
t_{f} & =2.54 \times 10^{-3} \mathrm{~m}\end{aligned}$ & $\begin{array}{l}1.893 \\
1.903 \\
2.015\end{array}$ & $\begin{array}{l}2.033 \\
2.042 \\
2.150\end{array}$ & $\begin{array}{l}2.159 \\
2.169 \\
2.282\end{array}$ \\
\hline \multirow[b]{3}{*}{2} & \multicolumn{2}{|l|}{ Libove (1984) } & 5.908 & 5.195 & 4.512 \\
\hline & \multicolumn{2}{|l|}{ MODEL III } & 5.903 & 5.183 & 4.528 \\
\hline & MODEL II & $\begin{aligned} t_{f} & =2.54 \times 10^{-5} \mathrm{~m} \\
t_{f} & =2.54 \times 10^{-4} \mathrm{~m} \\
t_{f} & =2.54 \times 10^{-3} \mathrm{~m}\end{aligned}$ & $\begin{array}{l}5.906 \\
5.983 \\
6.364\end{array}$ & $\begin{array}{l}5.201 \\
5.234 \\
5.654\end{array}$ & $\begin{array}{l}4.533 \\
4.570 \\
5.016\end{array}$ \\
\hline
\end{tabular}
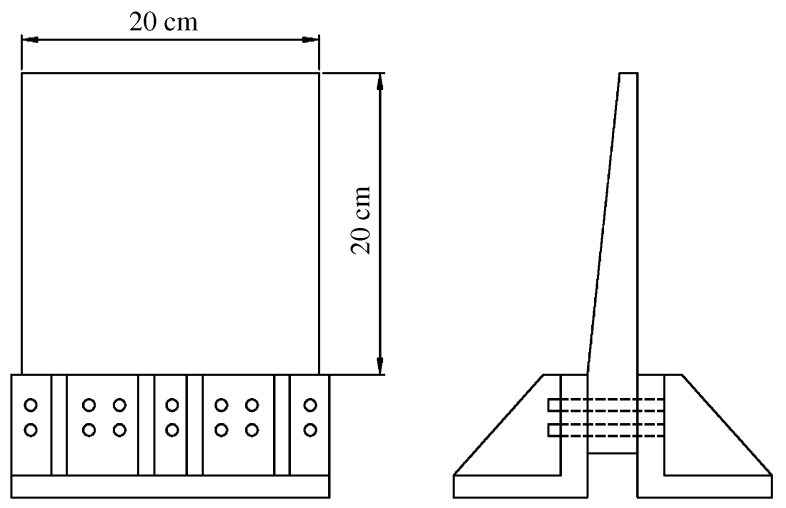

Fig. 4 Specimen and its method of fixation

The material constants of hard PU foam of core can be obtained via Young's modulus, density and shear modulus test according to standards of ASTM D1621-73, ASTM D1622-63 and ISO1922-1981. The material type of aluminum face plate is 6061-T6. Material constants for the test specimen are listed as follows,

Aluminum

$$
\begin{aligned}
& E_{f}=68.67 \times 10^{9} \mathrm{~Pa}, v_{f}=0.345, \rho_{f}=2700 \mathrm{~kg} / \mathrm{m}^{3}, \\
& t_{f}=1.61 \times 10^{-3} \mathrm{~m}
\end{aligned}
$$

PU foam

$$
\begin{aligned}
& E_{c}=34.9 \times 10^{6} \mathrm{~Pa}, G_{c}=18.96 \times 10^{6} \mathrm{~Pa}, \\
& \rho_{c}=114.5 \mathrm{~kg} / \mathrm{m}^{3}
\end{aligned}
$$

Adhesive film

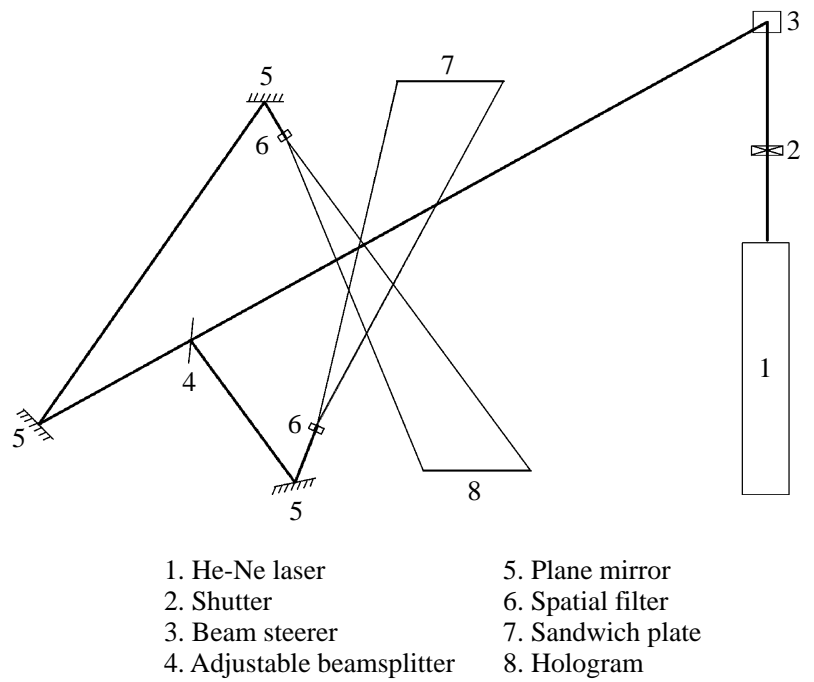

Fig. 5 Arrangement of laser path

$$
\rho_{c}=0.3 \mathrm{~kg} / \mathrm{m}^{2}
$$

A $10 \times 10$ element is adopted to mesh the specimen uniformly, according to the requirements of concentrated load and convergence of high order mode of vibration.

\section{Static Experimental Results and Comparisons under Concentrated Load}

Static experiments were executed by double exposure method to investigate the light interference of specimen before and after the concentrated load being applied. The holographic interference fringes are digitized and then compared with numerical predictions. The positions of concentrated loads are shown in Fig. 6. Two loading cases are considered: one is $200 \mathrm{~g}$ 


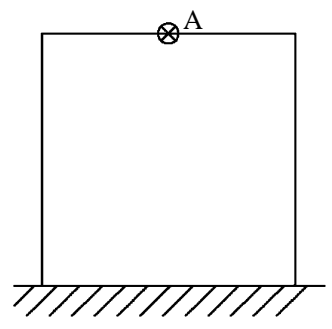

(a) Applied at middle point $\mathrm{A}$

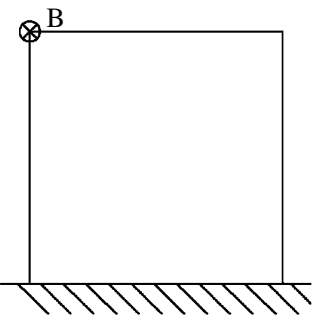

(b) Applied at corner B
Fig. 6 Position of concentrated load
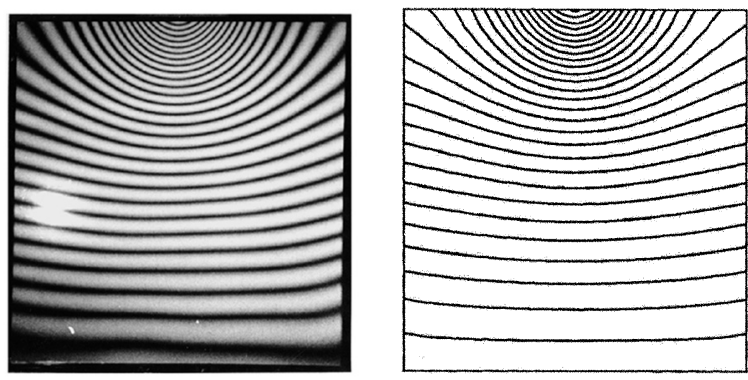

(a) $200 \mathrm{~g}$ Concentrated load applied at middle point
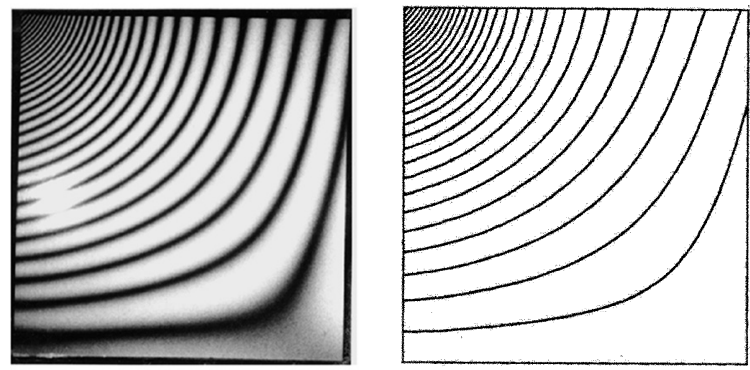

(b) $100 \mathrm{~g}$ Concentrated load applied at left upper corner

Fig. 7 Holograms (left) and contours (right) of displacement of aluminum sandwich plate with $\beta=0.5$ under concentrated loading

applied at middle point $\mathrm{A}$, and the other is $100 \mathrm{~g}$ applied at corner point $\mathrm{B}$. The numerical results of MODEL I are plotted as contours of transverse displacements which correspond to the fringes of holographic interference. For an example, $\beta=0.5$, the results of experimental data and numerical predictions are shown in Fig. 7, which indicates that the numerical predictions are in good agreement with the experimental data in trend and fringe numbers. A detailed comparison for the transverse displacement at the opposite side of the forced point applied at the middle of the free edge is selected, as shown in Fig. 8. The displacements predicted by the three models and from the experiments are compared. It is observed that MODEL I has the best agreement with experimental measurement. MODEL II yields an acceptable solution. However, MODEL III produces unacceptable predictions, due to the neglect of the bending effect of the face plates.

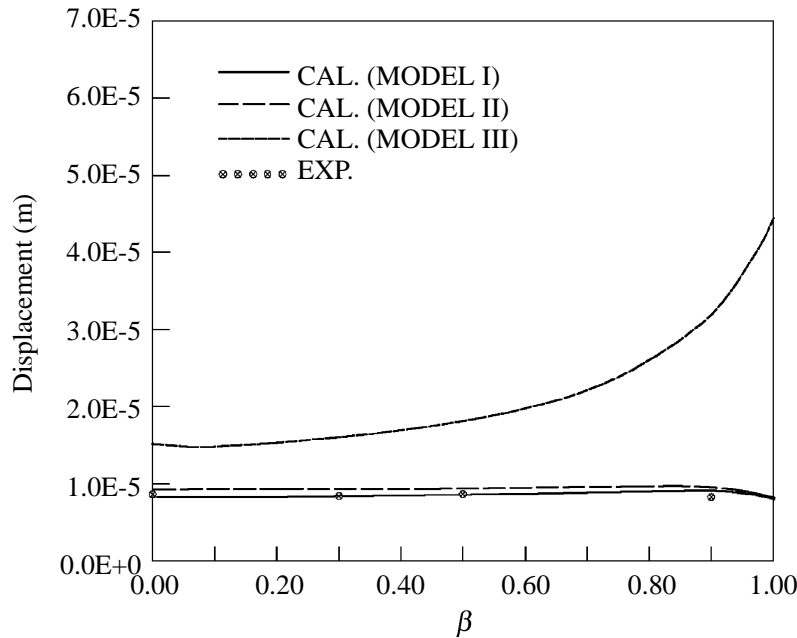

Fig. 8 Displacement of opposite side of forced point of aluminum sandwich plate with $200 \mathrm{~g}$ concentrated load applied at middle point of free edge

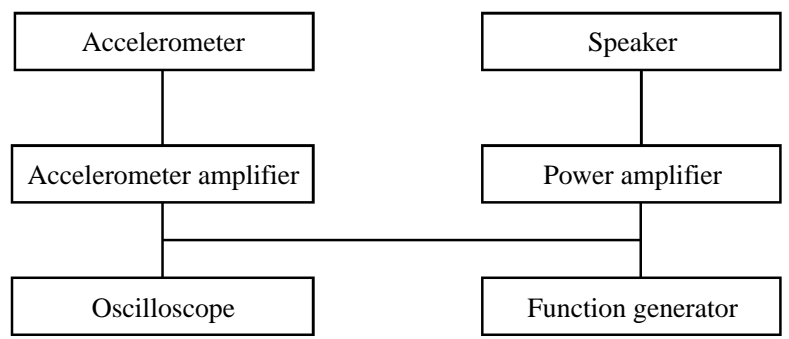

Fig. 9 The arrangement of exciting and measuring of vibration of sandwich plate

\section{Dynamic Experimental Results and Compari- sons under Forced Vibration}

The purposes of the dynamic experiment are measuring natural frequency and recording modes of resonance. Wet processing of real time holographic interferometry (Achia, 1972; Biedermann, 1970) is used to identify the resonant response. To obtain a clearer hologram, vibration mode is recorded by time-average holographic interferometry. The arrangement of the excitement and the measuring of the vibration of sandwich plate is shown in Fig. 9. The vibration of the specimen is induced by sound waves behind the plate about $1 \mathrm{~mm}$, which are produced by a speaker after inputting the signals produced by a generator and magnified by an amplifier. The vibration of sandwich plates can be observed immediately through a hologram which contains the interference fringes resulting from the light of the vibrational object and the virtual image of the static object, when the specimen is vibrating. Tuning the frequency of the function generator slowly, until a stable and clear fringe map occurs, the state is one of the vibration modes and the frequency is the 
Table 2 Natural frequencies of aluminum sandwich plate obtained by experiment and numerical calculation. Mode number shown is the mode frequency order for the flat plate, and $(m, n)$ is the number of nodal lines in the mode shape, parallel to $\boldsymbol{y}$-axis and $\boldsymbol{x}$-axis respectively

\begin{tabular}{|c|c|c|c|c|c|c|c|c|c|c|c|c|}
\hline \multirow[b]{2}{*}{ Mode } & \multicolumn{3}{|c|}{$\beta=0.0$} & \multicolumn{3}{|c|}{$\beta=0.3$} & \multicolumn{3}{|c|}{$\beta=0.5$} & \multicolumn{3}{|c|}{$\beta=0.9$} \\
\hline & $\begin{array}{l}\text { EXP. } \\
(\mathrm{Hz})\end{array}$ & $\begin{array}{c}\text { NUM. } \\
(\mathrm{Hz})\end{array}$ & $\begin{array}{c}\text { ERR. } \\
(\%)\end{array}$ & $\begin{array}{l}\text { EXP. } \\
(\mathrm{Hz})\end{array}$ & $\begin{array}{c}\text { NUM. } \\
(\mathrm{Hz})\end{array}$ & $\begin{array}{c}\text { ERR. } \\
(\%)\end{array}$ & $\begin{array}{l}\text { EXP. } \\
(\mathrm{Hz})\end{array}$ & $\begin{array}{c}\text { NUM. } \\
(\mathrm{Hz})\end{array}$ & $\begin{array}{c}\text { ERR. } \\
(\%)\end{array}$ & $\begin{array}{l}\text { EXP. } \\
(\mathrm{Hz})\end{array}$ & $\begin{array}{c}\text { NUM. } \\
(\mathrm{Hz})\end{array}$ & $\begin{array}{c}\text { ERR. } \\
(\%)\end{array}$ \\
\hline $1(0,0)$ & 229 & 219 & -4.2 & 238 & 235 & -1.5 & 251 & 248 & -1.4 & 296 & 286 & -3.4 \\
\hline $2(0,1)$ & 413 & 397 & -3.8 & 395 & 384 & -2.7 & 389 & 379 & -2.6 & 399 & 388 & -2.9 \\
\hline $3(1,0)$ & 730 & 693 & -5.0 & 688 & 664 & -3.5 & 663 & 644 & -2.9 & 625 & 604 & -3.4 \\
\hline $4(1,1)$ & 905 & 858 & -5.2 & 860 & 822 & -4.4 & 826 & 797 & -3.5 & 792 & 753 & -4.9 \\
\hline $5(0,2)$ & 997 & 948 & -5.0 & 939 & 888 & -5.4 & 887 & 844 & -4.8 & 814 & 757 & -7.1 \\
\hline $6(1,2)$ & 1294 & 1231 & -4.9 & 1243 & 1180 & -5.1 & 1188 & 1144 & -3.7 & 1141 & 1075 & -5.8 \\
\hline $7(2,0)$ & 1337 & 1281 & -4.2 & 1285 & 1228 & -4.5 & 1232 & 1188 & -3.6 & 1180 & 1104 & -6.4 \\
\hline $8(1,3)$ & 1457 & 1389 & -4.7 & 1390 & 1332 & -4.2 & 1331 & 1289 & -3.2 & 1252 & 1179 & -5.8 \\
\hline $9(0,3)$ & 1522 & 1461 & -4.0 & 1459 & 1378 & -5.6 & 1374 & 1317 & -4.2 & 1269 & 1215 & -4.2 \\
\hline $10(2,2)$ & 1760 & 1701 & -3.4 & 1722 & 1639 & -4.8 & 1636 & 1594 & -2.6 & 1587 & 1507 & -5.1 \\
\hline $11(1,3)$ & 1834 & 1737 & -5.3 & 1772 & 1672 & -5.7 & 1688 & 1625 & -3.8 & 1630 & 1531 & -6.1 \\
\hline $12(3,0)$ & 2027 & 1945 & -4.1 & 1942 & 1874 & -3.5 & 1858 & 1822 & -2.0 & 1790 & 1708 & -4.6 \\
\hline $13(3,1)$ & 2109 & 2039 & -3.3 & 2023 & 1969 & -2.7 & 1950 & 1917 & -1.7 & 1880 & 1810 & -3.8 \\
\hline $14(0,4)$ & 2260 & 2166 & -4.2 & 2167 & 2058 & -5.0 & 2055 & 1974 & -3.9 & 1868 & 1799 & -3.7 \\
\hline $15(2,3)$ & 2273 & 2169 & -4.6 & 2208 & 2100 & -4.9 & 2118 & 2050 & -3.2 & 2056 & 1954 & -5.0 \\
\hline $16(3,2)$ & 2408 & 2322 & -3.6 & 2332 & 2251 & -3.5 & 2245 & 2198 & -2.1 & 2190 & 2093 & -4.4 \\
\hline
\end{tabular}

so-called resonant frequency at this vibration mode. In order to ensure that the vibration is not the combined response of multiple modes, a subminiature accelerometer is attached at different locations on the plate to measure the vibration frequency.

During the dynamic experiments, the natural frequencies and vibration modes of the lowest 16 orders were measured for every specimen of sandwich plate. Because of the anti-symmetric nature of most of the vibration modes and the importance of the bending effect, the numerical simulations were performed based on the analytic MODEL II for comparison. Comparison results of the natural frequencies are shown in Table 2 and the errors are under $7.1 \%$. For the purpose of comparison and ensuring every frequency measured in experiments is the true natural frequency, every vibration mode of each specimen had a hologram taken and it then was compared with the numerical prediction of the vibration mode. Taking $\beta$ $=0.5$ as an example, the vibration modes recorded from the experiments and predicted by numerical simulation are shown in Fig. 10, respectively. It is easily observed that the consistency between the experiments and the numerical predictions is extremely good.

It can be inferred from the above discussions, that responses of vibration and the frequencies of vibration modes can be predicted correctly by MODEL II. Especially, the mode transfer phenomenon, occurring between mode 13 and 14, as shown in Table 2 , induced by the change of taper. constant $\beta$, can be grasped, too.

From the numerical and the experimental results, we can see that the natural frequencies decrease as the taper constant $\beta$ increases except for modes 1 and 2. The natural frequencies of the sandwich plate are affected by the dual factors, namely, the local stiffness of the sandwich plate and the effect of variable thickness. As $\beta$ increases, the local stiffness of the sandwich plate decreases due to the smaller local thickness while the effect of variable thickness increases (which is equivalent to raising the stiffness of bending). At lower modes, the effect of variable thickness has a larger impact on the sandwich plate. However, at higher modes with more nodal lines, the effect of a decrease in the local stiffness of sandwich plate overwhelms the effect of variable thickness and therefore decreases the natural frequency.

\section{CONCLUSIONS}

In this paper, three numerical models are proposed. Based on these models, finite element codes have been developed to solve the deflection and vibration problems of aluminum sandwich plates with variable thickness. The deformation of face plates and core is assumed to vary linearly along the thickness direction. Membrane force, bending moment, shear force and various coupled forces are all taken into account. Marguerre shell theory is adopted to handle the effect of variable thickness of core or non-flatness of the face plates of shallow shell type sandwich plates.

From the comparison of our numerical simulation with the existing solutions in the literature, some observations can be concluded. The most important 

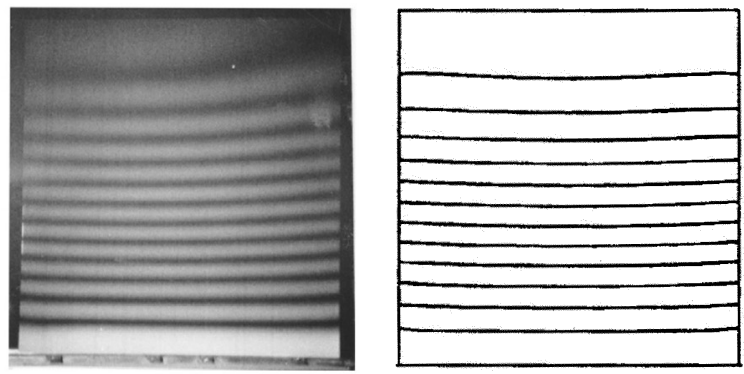

mode 1
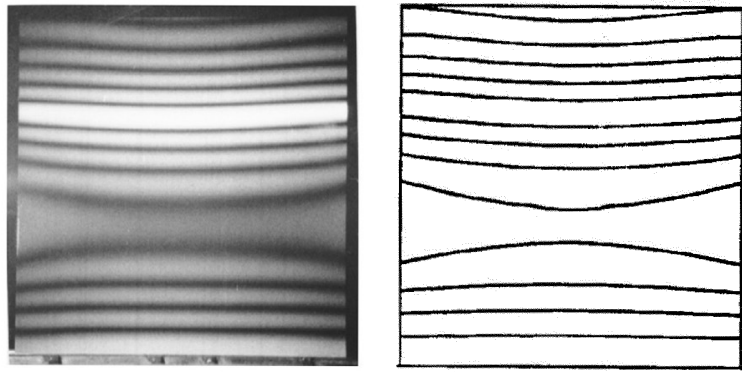

mode 3
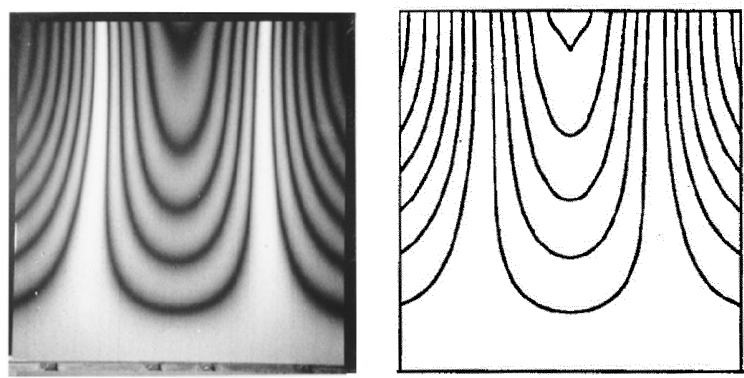

mode 5
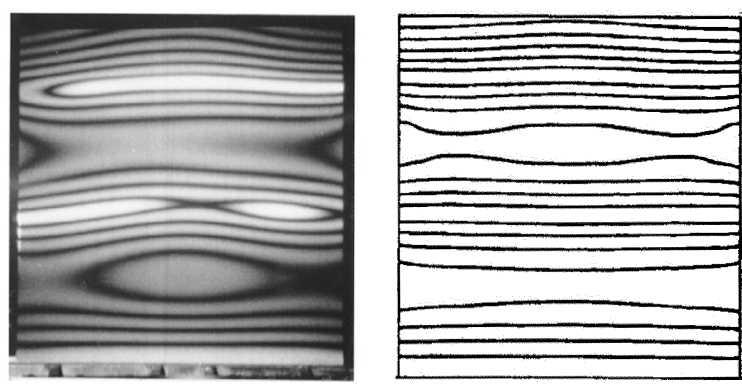

mode 7
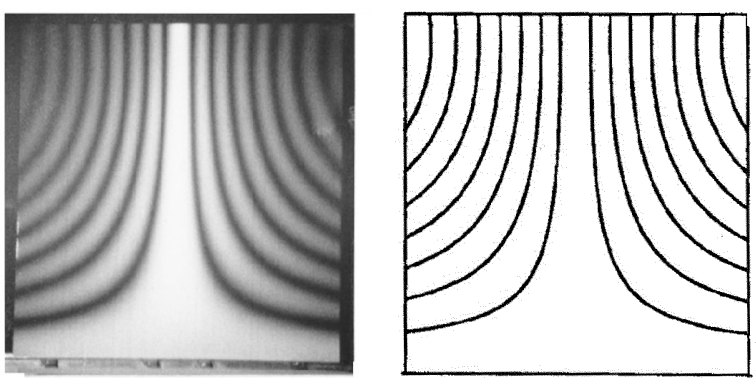

mode 2
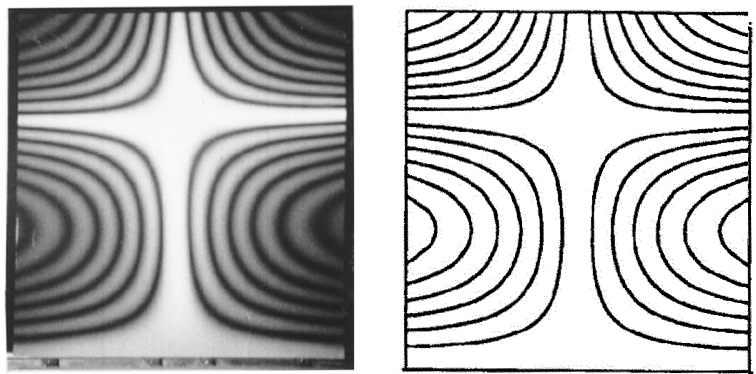

mode 4
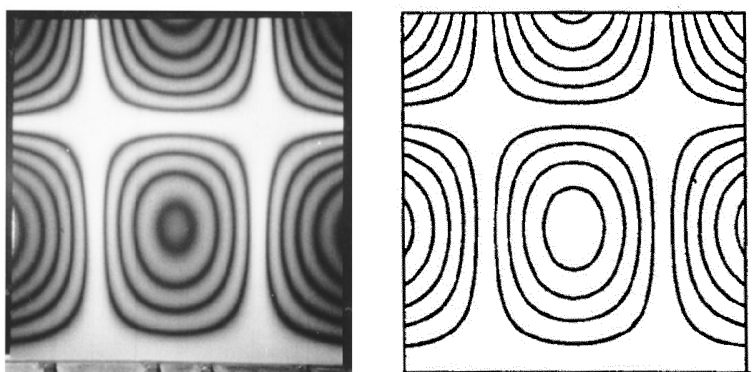

mode 6
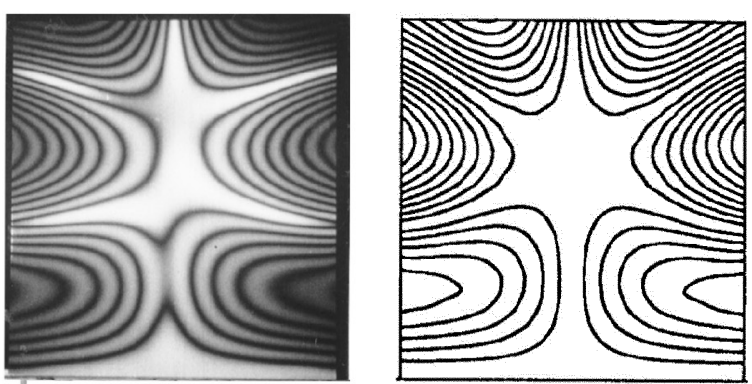

mode 8

Fig. 10 (a) Holograms (left) and contours (right) of vibration modes of aluminum sandwich plate with $\beta=0.5$, mode $1 \sim 8$

parameters which affect the behaviors of sandwich plate of variable thickness are the ratio of flexural stiffness to transverse shear stiffness, slope of the core, and thickness ratio of face plate to core. Large errors can be produced, if bending effect of the face plates is neglected. The effect of variable thickness on frequency reaches its maximum at the lowest vibration mode, and decreases when the vibration mode gets higher; on the other hand, the effect of bending stiffness of face plate increases when the vibration mode goes down.

The holographic interferometry experiments have verified the correctness of analytic modes proposed in this paper. It is shown that MODEL I can simulate the deflection of a specimen in a static loading experiment. In addition, the simpler MODEL II can predict the natural frequencies and vibration modes sufficiently accurately, too. 

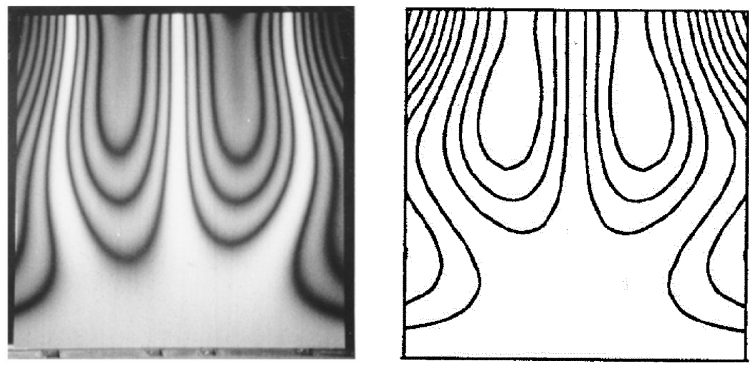

mode 9
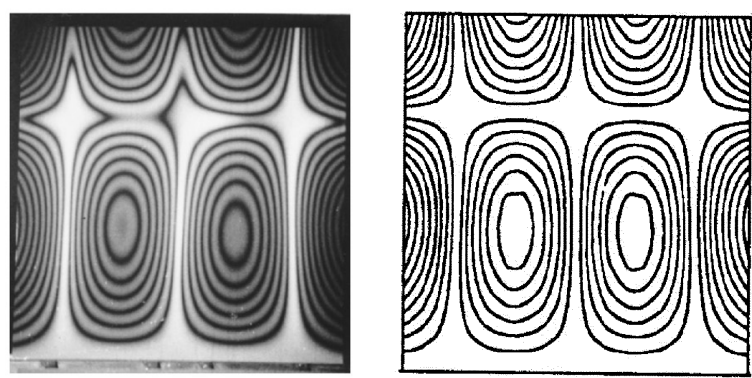

mode 11
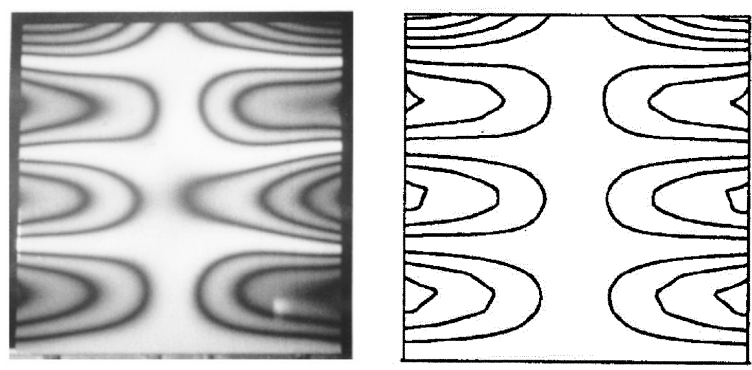

mode 13
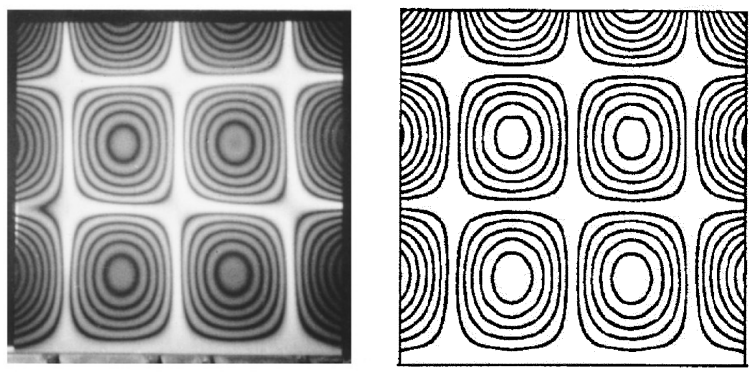

mode 15
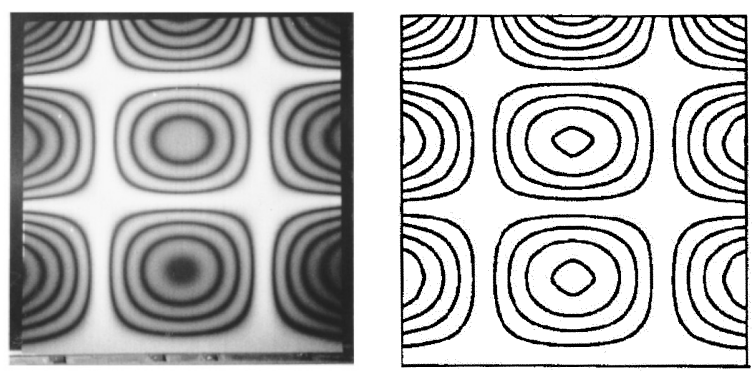

mode 10
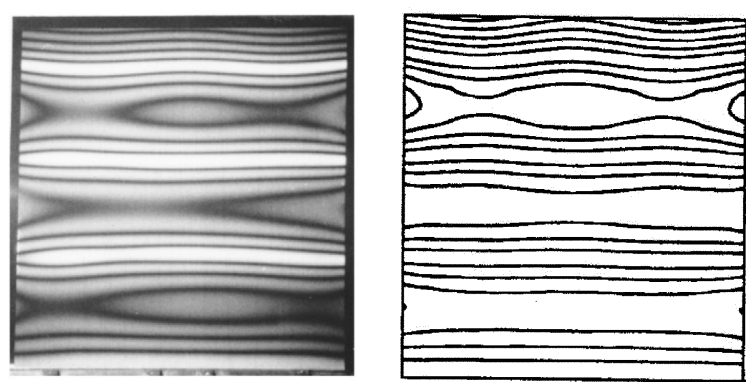

mode 12
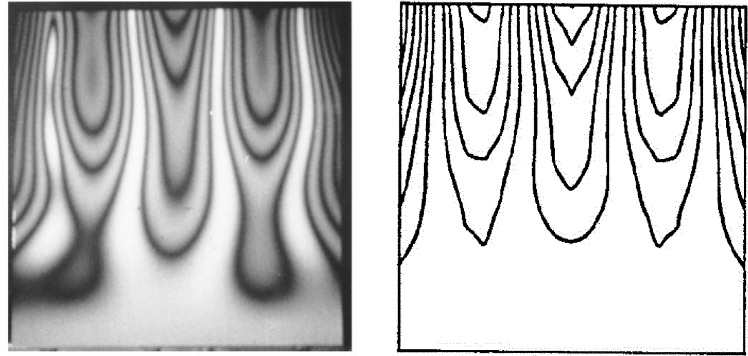

mode 14
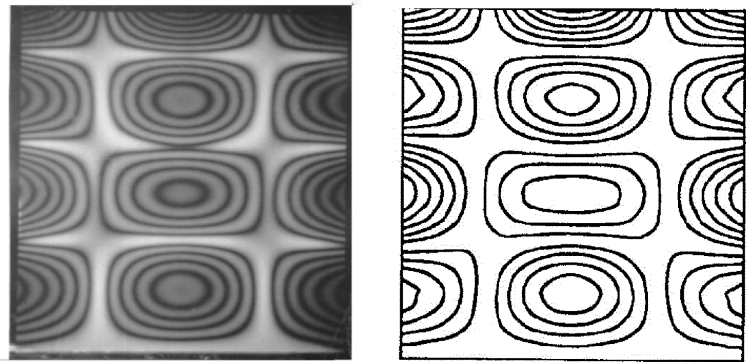

mode 16

Fig. 10 (b) Holograms (left) and contours (right) of vibration modes of aluminum sandwich plate with $\beta=0.5$, mode $9 \sim 16$

NOMENCLATURE

$d_{1}, d_{2} \quad$ a half of the thickness of upper and lower face plates $(\mathrm{m})$

$E_{c}, E_{f} \quad$ Young's modulus of the core and the face plates $\left(\mathrm{N} / \mathrm{m}^{2}\right)$

$e_{c z} \quad$ normal strains on the $z$ plane of the core deformation $e_{f} \quad$ in-plane strains of the face plates

$e_{f 0} \quad$ total membrane strains at the face plate of mid-plan

$e_{f 01} \quad$ general membrane strains

$e_{f 02}$

$f$

$[G]_{c}$ additional linear membrane strains due to the undeformed shape of the face plate $f=1,2$ denotes upper and lower face plates respectively

transverse shear modulus matrix of the 


$\begin{array}{lll}G_{c y^{\prime} z}, G_{c x^{\prime} z} & \begin{array}{l}\text { core }\left(\mathrm{N} / \mathrm{m}^{2}\right) \\ \text { transverse shear modulus of the core } \\ \text { principal axes } x^{\prime} y^{\prime} z\left(\mathrm{~N} / \mathrm{m}^{2}\right)\end{array} & \begin{array}{l}v_{f} \\ \theta_{c}\end{array} \\ h_{c} & \begin{array}{l}\text { thickness at an arbitrary point of the core } \\ (\mathrm{m})\end{array} & \theta_{f x}, \theta_{f y} \\ h_{c 0} & \text { reference thickness of the core }(\mathrm{m}) & \rho_{a} \\ k_{f 0} & \begin{array}{l}\text { bending strains } \\ N_{i}\end{array} & \rho_{c} \\ {\left[\bar{Q}_{f}\right.} & \begin{array}{l}\text { shape functions } \\ \text { matrices of the transformed reduced stiff- }\end{array} & \sigma_{c z} \\ \bar{Q}_{i j} & \begin{array}{l}\text { ness of the face plates }\left(\mathrm{N} / \mathrm{m}^{2}\right) \\ \text { transformed reduced stiffness }\left(\mathrm{N} / \mathrm{m}^{2}\right)\end{array} & \left\{\sigma_{f}\right\},\left\{\tau_{f}\right\} \\ q, q_{0} & \begin{array}{l}\text { loading and amplitude }\left(\mathrm{N} / \mathrm{m}^{2}\right) \\ \text { ratio of bending stiffness and transverse }\end{array} & \omega \\ R & \begin{array}{l}\text { shear stiffness } \\ \text { position vectors of an arbitrary point on } \\ \text { the mid-plane of face plates }(\mathrm{m})\end{array} & \omega_{r} \\ \boldsymbol{r}_{f}^{(0)} & \begin{array}{l}\text { position vectors of an arbitrary point of } \\ \text { the face plate before and after deforma }\end{array} & \\ \boldsymbol{r}_{f}^{(i)}, \boldsymbol{r}_{f}^{(f)} & \end{array}$

Poisson's ratio of the face plates angle between the principal axes $x^{\prime} y^{\prime}$ of the core and global axes $x y$ (rad) deformed angles of mid-plane of face plate $f$ on $x z$ and $y z$ plane (rad) density of the adhesive film $\left(\mathrm{kg} / \mathrm{m}^{2}\right)$ density of the face plate and the core $(\mathrm{kg} /$ $\mathrm{m}^{3}$ ) normal stresses on the $z$ plane of the core $\left(\mathrm{N} / \mathrm{m}^{2}\right)$

Allen, H. G., 1969, Analysis and Desigh of Structural Sandwich Panels, Pergamon Press, Oxford, UK.

Achia, B. U., 1972, “A Simple Plateholder for on Site Wet Processing of Holograms in Real - Time Holographic Interferometry," Journal of Physics E: Scientific Instruments, Vol. 5, pp. 128-129.

Bathe, K. J., 1982, Finite Element Procedures in Engineering Analysis, Prentice-Hall Inc., Englewoods Cliff, NJ, USA.

Biedermann, K., and Molin, N. E., 1970, "Combining Hypersensitization and Rapid in Situ Processing for Time - Average Observation in Real - Time Hologram Interferometry," Journal of Physics E: Scientific Instruments, Vol. 3, pp. 669-680.

Chang, J. S., and Chen, H. C., 1992, "Free Vibrations of Sandwich Plates of Variable Thickness," Journal of Sound and Vibration, Vol.155, No. 2, pp. 195-208.

Huang, S. N., and Alspaugh, D. W., 1974, "Minimum Weight Sandwich Beam Desigh," AIAA Journal, Vol. 12, pp. 1617-1618.

Jones, R.M., 1975, Mechanics of Composite Materials, McGraw-Hill, New York, USA.

Lee, Y. J., and Yu, J. X., 1985, "Study on the Buckling Strength of Sandwich Structures," NTU-INA Technical Report 206, National Taiwan Univdersity, Taiwan.

Libove, C., 1984, "Variable-Thickness Sandwich Plates: Beam-Like Bending and Vibration of Plates Symmetric About a Middle Surface," Report MAE-5471-1., Syracuse University, Syracuse, NY, USA.

Libove, C., and Lu, C. H., 1989, "Beam-Like Bending of Variable-Thickness Sandwich Plates," AIAA Journal, Vol. 27, N. 4, pp. 500-507.

Lu, C. H., and Libove, C., 1991, "Beam-Like Harmonic Vibration of Variable-Thickness Sandwich 
Plates," AIAA Journal, Vol. 29, N. 2, pp. 299305.

Marguerre, K., 1938, “Zur Theorie der gekrümmten Platte großer Formänderung," Proceedings of the 5th International Congress for Applied Mechanics, pp. 93-101.

Paydar, N., 1985, "Stress Analysis of Variable Sandwich Plates of Rectangular Planiform," ASME Journal of Applied Mechanics, Vol. 53, pp. 609613.

Paydar, N., and Libove, C., 1986, "Stress Analysis of Sandwich Plates with Unidirectional Thickness Variation," ASME Journal of Applied Mechanics, Vol. 53, pp. 609-613.

Paydar, N., and Libove, C., 1988, "Bending of Sandwich Plates of Variable Thickness," ASME Journal of Applied Mechanics, Vol. 55, pp. 419-424.

Paydar, N., 1988, "Stress Analysis of Annular Sandwich Plates of Linearly Varying Thickness," International Journal of Solids Structures, Vol.24, pp. 313-320.

Pica, A., and Wood, R. D., 1980, "Postbuckling Behaviour of Plates and Shells Using a Mindlin Shallow Shell Formulation," Computers \& Structures,
Vol. 12, pp. 759-768.

Plantema, F. J., 1969, Sandwich Construction, Wiley, New York, USA.

Reissner, E., 1947, "On Bending of Elastic Plates," Quarterly of Applied Mathematics, Vol. 5, pp. 55-58.

Reissner, E., 1948, "Finite Deflections of Sandwich Plates," Journal of Aeronautical Science, Vol. 15, pp. 435-440.

Washizu, K., 1975, Variational Methods in Elasticity and Plasticity, 2nd ed., Pergamon Press Ltd, New York, USA.

Yu, Y. Y., 1960a, "Flexural Vibrations of Elastic Sandwich Plates," Journal of Aeronautical Science, Vol. 27, pp. 272-282, 290.

Yu, Y. Y., 1960b, "Simplified Vibration Analysis of Elastic Sandwich Plates," Journal of Aeronautical Science, Vol. 27, pp. 894-900.

Zienkiewicz, O. C., 1971, The Finite Element Method, 3rd ed., McGraw-Hill Book Co., Ltd. UK.

Manuscript Received: May 13, 2005

Revision Received: Sep. 15, 2005

and Accepted: Oct. 06, 2005 